\title{
A potência feminista a partir de um olhar histórico: a Tribuna da Primeira Conferência Mundial da Mulher e o desejo de transformar tudo
}

\author{
La potencia feminista from a historical view: The Tribune of the World Conference of the International \\ Women's Year and the desire to change everything
}

DOI: https://doi.org/10.22456/2178-8839. 113860

Natali Francine Cinelli Moreira Instituto de Relações Internacionais da Universidade de São Paulo, São Paulo, Brasil natalicinelli@usp.br 9

Kelly Komatsu Agopyan Instituto de Relações Internacionais da Universidade de São Paulo, São Paulo, Brasil kelly.agopyan@usp.br

\section{Resumo}

Verónica Gago desenvolve a potência feminista como teoria alternativa de poder. A partir das múltiplas opressões que recaem sobre as mulheres, a autora teoriza o desejo de transformar tudo. Propomos revisitar as discussões da Tribuna da Primeira Conferência Mundial da Mulher,1975, a partir da potência feminista. Em meio à Guerra Fria, milhares de mulheres - do sul e do norte globais, de países socialistas e capitalistas - se reuniram pela primeira vez para discutir seu papel na sociedade. As mulheres se reuniram na Tribuna e tornaram-se visíveis; em assembleia, discutiram as opressões a que eram submetidas. As discussões foram numerosas, as diferenças se multiplicaram e as unanimidades foram escassas, mas é possível en contrar na Tribuna um embrião da potência feminista como capacidade desejante que segue impulsionando a luta histórica pela igualdade. Por meio da análise de documentos históricos e de relatos das participantes, concluímos ser evidente o desejo das participantes de mudar as estruturas de poder e deslocar os limites a que foram submetidas, mesmo em sua heterogeneidade. Revisitando a literatura de difusão internacional, concluímos, ainda, que a Tribuna deixou valiosas contribuições, difundidas e traduzidas de forma transnacional, e que ainda hoje orientam os movimentos feministas.
\end{abstract}

Palavras-chave: Teoria feminista; Tribuna da Primeira Conferência Mundial da Mulher; Difusão internacional de ideias;

\begin{abstract}
Verónica Gago theorizes la potenciafeminista as an alternative theory of power. Departing from the multiple forms of oppression that subjugate women, the author theorizes the desire to change everything. We propose to revisit the discussions held at the Tribune of the World Conference of the International Women's Year, 1975, through la potencia feminista. Amidst the Cold War, thousands of women - from the global south and north, from socialist and capitalist countries - gathered for the first time to discuss their role in society. These women gathered at the Tribune and made themselves visible; in assembly, they discussed the multiple forms of oppression to which they were subjected. Discussions abounded, differences multiplied, and unanimities were scarce. Yet, we found at the Tribune an embryo of la potenciafeminista as the desiring capacity which still spurs the historical fight for equality. Departing from historical documents and direct reports from those who attended the event, we conclude that it is evident the desire of those women to change power structures and to displace the limits to which they were subjected to, even among their own heterogeneity. Relying on the international diffusion literature, we also conclude that the Tribune left valuable contributions that were transnationally spread and translated, which still nowadays orient feminist movements.
\end{abstract}

Keywords: Feminist theory; Tribune of the World Conference of the International Women's Year; International diffusion of ideas; 


\section{Introdução}

Verónica Gago (2020) apresenta a potência feminista como uma teoria alternativa de poder. Para a autora, a potência feminista - entendida a partir da multiplicidade dos feminismos e dos diversos sujeitos que sofrem com as violências machistas, incluindo-se mulheres, lésbicas, travestis, trans e não binários (VILAÇA; FREITAS, 2020) - permite reivindicar a indeterminação do que estes sujeitos podem ser, para além dos limites que tradicionalmente lhes são impostos. A autora utiliza-se da greve feminista como catalisador para desenvolver a potência feminista como um contrapoder. Retira-se a greve de seu ambiente trabalhista e sindical habitual, majoritariamente masculino, heterossexual e branco, e a traz para o movimento feminista. Nesse movimento, ao aproximar a greve dos sujeitos marginalizados representados pelos feminismos, é possível identificar a precariedade e o regime de invisibilidade sobre as formas de trabalho e produção de valores por estes sujeitos e utilizá-la como espaço para desafiar e cruzar papéis predeterminados. A greve feminista é, assim, o ponto de partida de Verónica Gago para teorizar a potência feminista como capacidade desejante de contestar, deslocar limites e transformar tudo.

Nesse artigo, sugerimos utilizar outro evento emblemático da luta histórica das mulheres por igualdade como uma lente - em sentido analítico e prático - para compreender a potência feminista proposta por Verónica Gago. Se a potência feminista é um "pensamento situado em uma sequência de lutas" (GAGO, 2020, p.10), propomos um olhar para o passado para revisitar um evento que é tido como divisor de águas do feminismo transnacional: a Tribuna da Primeira Conferência Mundial da Mulher de 1975 (“Tribuna”). Ao retomar os encontros na Tribuna, é evidente a inteligência coletiva que emergiu do encontro daquelas mulheres e o desejo de mudança que carregaram consigo para a própria Tribuna, mas, também, posteriormente, para suas lutas em seus contextos nacionais e sociais diversos. Os debates foram múltiplos, as discordâncias ficaram escancaradas, e as unanimidades foram escassas. Ainda assim, é manifesto o repúdio das estruturas de poder que as submetiam a papéis ancestrais de gênero e nãolhes permitia reivindicar tudo que poderiam ser (OLCOTT, $2017 ; 2010)$.

O presente artigo possui dois objetivos principais. O primeiro deles é revisitar a Tribuna sob a luz da potência feminista. Com isso, quer-se demonstrar que ali havia um embrião da capacidade desejante que segue impulsionando a luta pela igualdade, ainda que naquele momento a potência feminista não fosse compreendida como teoria. Documentos históricos e relatos das participantes orientam nossa análise, e nos permitem concluir que a consciência coletiva sobre a nossa precariedade e o desejo de transformar papéis impostos já se faziam presentes nesse evento ocorrido há mais de quatro décadas. O segundo é demonstrar o alcance das ideias discutidas na Tribuna, sendo essa um lócus para a difusão internacional. Mobilizamos a literatura de difusão para discutir como o encontro entre os diversos feminismos na Tribuna produziu suas próprias sementes que foram espalhadas no retorno dessas vozes para suas casas.

$\mathrm{O}$ artigo seguirá da seguinte forma. Na próxima seção, exploraremos a potência feminista. Na sequência, apresentaremos um breve histórico da Tribuna. Sugerimos que um embrião da potência feminista já se fazia presente na inteligência coletiva e na capacidade desejante presentes na Tribuna. É sob o legado dessas discussões que discutimos, em seguida, como ideias produzidas, circuladas e legitimadas na Tribuna foram difundidas internacionalmente e ainda seguem informando debates feministas contemporâneos. Por fim, concluiremos.

\section{A potência feminista de Verónica Gago}

Para Verónica Gago (2020), potência feminista significa reivindicar outro tipo de poder possível, alternativo à estrutura dominante neoliberal, imperialista e patriarcal. A potência feminista questiona o despojo dos serviços públicos e o Estado mínimo, que prioriza o individual e menospreza a rede de segurança coletiva; disputa a financeirização extrema e a cidadania pelo consumo, que sujeita o cidadão à eterna dependência econômica; impõe -se contra a exploração neoextrativista, que devasta territórios e as vidas de quem vive da exploração sustentável da natureza; contesta o desprezo 
pelas vidas das mulheres, a violência contra seus corpos e a invisibilização do seu trabalho. Contrapõe -se, assim, às múltiplas opressões entrelaçadas que se impõem sobre a mulher.

A potência feminista reclama às mulheres a indeterminação do que podem ser: “(...) é uma capacidade de fazer, instituir, afetar e criar que se diferencia do poder (...)” (GAGO, 2020, p. 292). É avocar novas formas de viver, reivindicandose experiências das quais não sabem que são capazes, e só as conhecem quando se deslocam os limites aos quais foram submetidas e obrigadas a obedecer. Se o poder dominante oferece às mulheres o doméstico, a esfera privada, o trabalho reprodutivo e o cuidado com a família, a potência feminista reclama a elas o público, o trabalho produtivo valorizado e a independência social e financeira.

O desejo de transformar a realidade que oprime as mulheres acompanha a potência feminista. Como capacidade desejante, a potência traduz-se em percepção, contestação, e ação para colocar novas vidas em prática. O potencial cognitivo do desejo é conhecer e reclamar para si e para as outras um destino diferente. Potência feminista é, sobretudo, mover-se pela força insubordinada que desobedece e desloca barreiras impostas pelo neoliberalismo, imperialismo e patriarcado. Não se trata de uma prática (ou teoria) ingênua, mas sim de uma proposta de transformação social integral, a qual não pode se olvidar do papel da mulher na manutenção-econômica, política, cultural -da sociedade.

A autora ressalta, ainda, que potência não existe em abstrato. Necessita de um corpo para transformaro desejo em ação. O corpo reúne experiências, expectativas, trajetórias e memórias, coletivas e individuais, e é esse corpo que se impõe e sai às ruas para reivindicar outro poder. Movido pela força desejante, o corpo faz-se ver e ouvir ao encontrar-se com outros corpos tomados pelo mesmo desejo. Reunindo-se em espaços de reivindicação-seja na greve, em assembleias, em conferências, etc. -, os corpos tornam-se sujeitos políticos e contestam a posição de subordinação e de vitimização a qual as mulheres são submetidas.

Percebe-se, assim, que a potência feminista dialoga com o conceito de gênero apresentado por Judith Butler (2018). Para Butler, gênero é performativo. Ninguém é um gênero desde o início; as mulheres atuam e reproduzem atos que lhes são impostos ao longo do tempo. O modo como as mulheres comportam-seé imposto por normas reiteradas que representam uma forma de poder social, e adquirem alguma visibilidade apenas se a tuam conforme essas regras (MAIA, 2019). Essas convenções sãovazias de sentido e operam apenas como formas de poder sobre os corpos (RODRIGUES, 2019). Butler conclui que: “a reprodução do gêneroé, portanto, sempre uma negociação com o poder” (BUTLER, 2018, p. 27). E se as mulheres vivem sob regras de gênero, limitam-se ao que o poder dominante lhes determina e se privam do que podem ser.

Contudo, é dessa constante reprodução de convenções que surge a possibilidade de que as minorias venham a: “(...) desfazer ou refazer as normas de maneiras inesperadas, abrindo a possibilidade de reconstruir a realidade de gênero de acordo com novas orientações” (BUTLER, 2018, p. 27). A constante limitação das mulheres ao ambiente privado e domésticoé o que as impulsiona a: negar as regras e limites pré-estabelecidos e explorar um novo caminho para que suas vidas se tornem mais possível e suportável.

No contexto dessa reconstrução da realidade de gênero, Butler (2018) sugere que a luta das mulheres seja levada às ruas, em aliança com outras minorias. Os corpos devem ser colocados "na reta, na barreira, na linha de frente" como resposta à vulnerabilidade, reconhecendo a precariedade para recusá-la (GAGO, 2020,p. 213).É na conexãodos corpos em assembleia que se demonstra que a performatividade política vai além do discurso, tornando-se ação concreta contra o poder estabelecido (GAGO, 2020; BUTLER, 2018).

No diálogo com Rosa Luxemburgo e Silvia Federici, Gago (2020) explora o aspecto material da opressão. A economia feminista é fundamental para reconhecer o diferencial de exploração sofrido pelas mulheres, em especial a invisibilização e depreciação do trabalho reprodutivo, bem como para desenhar processos alternativos à lógica capitalista. Apoiando-se no "patriarcado do salário" de Federici, Gago (2020, p. 150; 155) debate como o trabalho produtivo é dependente do reprodutivo, e, ao conceder-se salário apenas ao primeiro, aprisiona homens e mulheres na lógica do 
capital. Às mulheres, o trabalho reprodutivo não-remunerado significa dependência financeira e uma vida limitada ao doméstico, sem a oportunidade de explorar outros destinos (FEDERICI, 2019, p. 42 -46). E, a partir do argumento de que a “existência coetânea” de elementos não capitalistasé necessária para a expansão do capitalismo-como proposto por Rosa Luxemburgo-, Gago trabalha a ideia da cidadania pelo consumo e do endividamento da vida cotidiana como exploração de valor das minorias, capturando o valor futuro do seu trabalho e colocando-os em um ciclo de dependência. As “economias populares” são apresentadas como tentativa de ressignificar o trabalho reprodutivo, atendendo ao desejo antigo das mulheres de repensar a economia (GAGO, 2020, p. $153-154 ; 163 ; 176-185)$.

As greves feministas ocorridas entre 2016 e 2019 na Argentina - sua terra natal - são o instrumento utilizado por Gago para teorizar a potência feminista e conectar as diversas brutalidades que recaem sobre as mulheres. É o desejo de lutar contra o despojo neoliberal, que impulsiona as mulheres a se reunir-em ato performático-nas greves feministas.

Se Gago parte da greve para teorizar a potência feminista, sugerimos olhar para o passado para argumentar que essa potência há muito move as mulheres, ainda que, naquele momento, não houves se sido teorizada. A própria autora concede elementos para esse retorno. Ao referir-seà potência feminista comoum "pensamento situado em uma sequência de lutas” (GAGO, 2020, p. 10), nos impulsiona a voltar para um evento pioneiro, no qual mulheres de tod o o mundo se reuniram pela primeira vez para discutir sua situação - abordando temas fundamentais à potência, como a invisibilização do trabalho doméstico. Se a teoria se situa em um encadeamento de lutas, nada mais natural que recuperar uma das batalhas iniciais.

Revisitaremos, assim, a Tribuna da Primeira Conferência Mundial da Mulher e utilizaremos o evento comolente em duplo sentido para compreender a potência feminista (GAGO, 2020, p. 13 -14): em sentido analítico, a Tribuna escancarou as opressões às quais as mulheres são submetidas, a precariedade de sua existência, e a invisibilidade das suas formas de trabalho e de produção de valor; em sentido prático, é olugar no qual as mulheres se permitiram desafiar e cruzar os limites impostos. Na Tribuna, consolidam-se como agentes de suas vidas e questionam a posição de vítimas que lhes é familiar.

\section{A potência feminista na Tribuna da Primeira Conferência Mundial da Mulher}

Antes de nos aprofundar na Tribuna, faz-se necessário tecer breves linhas sobre o material utilizado e a metodologia. Para revisitar o evento, analisamos: documentos históricos obtidos na série Foreign Relations of the United States (FRUS), disponível em sítio eletrônico oficial; ${ }^{1}$ estudos compreensivos sobre o evento-em especial, aqueles apoiados em múltiplos arquivos ou em entrevistas (GHODSEE, 2018; OLCOTT, 2017; MCCARTHY, 2015; WHITAKER, 1975); e memórias narradas pelas participantes (CHUNGARA, 1978). Seguindo as lições de Trachtenberg (2006), o material foi interpretado criticamente de modo a extrair uma lógica dos acontecimentos e a integrá-los como parte de um todo, considerando o contexto da época. Sempre que possível, informações entre diferentes fontes foram cruzadas. E, ao interpretá-las, buscamos analisar de forma dedutiva se os debates e os relatos eram consistentes com a ideia de desunião entre as participantes na Tribuna.

\section{A Tribuna: encontro de conflituosidades}

As primeiras linhas da Carta das Nações Unidas, discutida na Conferência de São Francisco de 1945, reafirmam a fé na igualdade de direito entre homens e mulheres, tornando-se, assim, o primeiro instrumento internacional a

\footnotetext{
O FRUS pode ser obtido no sítio eletrônico do Office of the Historian, responsável por compilar documentos oficiais referentes à história da política externa dos Estados Unidos. Considerando a natureza da Tribuna e o ano em que foi realizada, analisamos todos os documentos disponíveis no FRUS de 1973 a 1976 dedicados aos assuntos de mulheres na Organização das Nações Unidas (Documents on the United Nations, Women's Issues): documentos 165 a 190. Os documentos diretamente citados neste trabalho estão referenciados individualmente ao final. Nãoé demasiado esclarecer, ainda, que não nos propusemos a realizar um estudo compreensivo sobre a Tribuna. Nossa proposta é resgatar debates e relatos para analisá-los sob a ótica da potência feminista.
} 
reconhecer a equidade de gênero como um direito humano. Nessa mesma conferência, e após extenso trabalho da brasileira Bertha Lutz, foi proposta a criação de uma comissão especial para tratar da discriminação contra a mulher no âmbito da ONU (LAVILLE, 2008). A Comissão sobre a Situação da Mulher foi criada em 1946, e, nas próximas décadas, teve um papel significativo na codificação de direitos e na análise da situação global das mulheres. ${ }^{2}$

A despeito das contribuições trazidas pela comissão, era claro que a situação das mulheres seguia desigual ao redor do mundo, tanto do ponto de vista formal como prático. Fazia-se necessário, portanto, fortalecer o reconhecimento universal de jure e defacto da equidade de gênero para uma verdadeira melhora na vida das mulheres. É com esse espírito que a Assembleia Geral da ONU proclamou 1975 como o Ano Internacional da Mulher, propondo-se a intensificação de ações para a promoção da igualdade de gênero e para a integração completa da mulher em programas de desenvolvimento e na manutenção da paz. ${ }^{3}$

Para celebrar o Ano Internacional das Mulheres, a ONU promoveu diversos eventos entre os dias 19 de junho e 2 de julho de 1975, na Cidade do México, incluindo-se a Primeira Conferência Mundial da Mulher. Trata-se do primeiro encontro no qual os Estados-membros da ONU enviaram delegações oficiais para discutir especificamente a situação das mulheres em seus países. A conferência intergovernamental contou com a participação de delegações enviadas por 125 Estados - númerobastante expressivo, considerando que a ONU contava com 133 membros naquele momento. Aolongo de 12 dias, mais de dois mil representantes debateram questões referentes à situação das mulheres em seus países, resultando na elaboração de dois documentos oficiais: o Plano de Ação e a Declaração do México. Nestes documentos, os Estados reconheceram a situação desigual das mulheres, bem como assumiram compromissos para melhorar a condição de vida delas, incluindo-se o acessoigualitário à educação, a maior participação na política e o acesso adequado à sa úde. ${ }^{4}$ Como em outros eventos dessa natureza, as delegações representavam os interesses de seus governos, e não era incomum que as mulheres recebessem direcionamento desde seus países de origem sobre como posicionar-se-direcionamento este quase semprefornecido por homens (GHODSEE, 2018, 2010; MCCARTHY, 2015). ${ }^{5}$

Utilizando-se da estrutura e do apoio financeiro da ONU, outros eventos foram realizados em paralelo à conferência intergovernamental para celebrar o Ano Internacional das Mulheres, e, dentre ele s, o que ganhou maior repercussão foi a Tribuna das organizações não governamentais. ${ }^{6}$ Se a Primeira Conferência Mundial da Mulher foi marcada pelo formalismo das reuniões intergovernamentais, a Tribuna caracterizou -se pela informalidade. Milhares de mulheres reuniram-se - estima-se entre quatro e seis mil participantes (OLCOTT, 2017, p. 248; GHODSEE, 2018, p. 146) sem as amarras de pertencer a delegações oficiais. ${ }^{7}$ Participantes da sociedade civil, desde grupos de natureza liberal até movimentos radicais de libertação, acadêmicos, profissionais, e curiosos, se reuniram na Tribuna para discutir a situação das mulheres nos seus países. A realização da Tribuna é evidência da crescente importância da sociedade civil no âmbito da ONU na década de 1970 (OLCOTT, 2017). ${ }^{8}$

Para evitar que a Tribuna fosse dominada por norte-americanas e europeias, as organizadoras preocuparam-se em assegurar a participação de mulheres de várias partes do mundo. Mais da metade do orçamento da Tribuna foi

\footnotetext{
2 A Comissão foi responsável por minutar tratados fundamentais para o combate da discriminação contra as mulheres como a Convenção sobre os Direitos Políticos das Mulheres (1953) e a Convenção sobre a Eliminação de Todas as Formas de Discriminação contra as Mulheres (1979).

3 A Assembleia Geral também proclamou a Década da Mulher, de 1976 até 1985. Ver ONU (1972) e ONU (1976).

${ }^{4}$ Ver ONU (1975).

5 É possível notar a presença de homens direcionando o trabalho de representantes femininas não só na conferência, mas também em outros encontros intergovernamentais dedicados à situação das mulheres. Nesse sentido, ver telegrama enviado pela missão norte-americana presente na $25^{\mathrm{a}}$ sessão da Comissão sobre a Situação da Mulher na ONU ao Departamento de Estado em 4 de fevereiro de 1974. A missão reporta que um representante masculino da delegação soviética interveio nas discussões, inclusive opondo-se à realização da conferência do México no âmbito do Ano Internacional da Mulher, e substituiu - alegadamente como tática de obstrução - a representante feminina que chefiava a delegação. Ver FRUS (2008a).

6 Além da Tribuna, realizou-se também um seminário sobre mulheres e desenvolvimento e um encontro de jornalistas.

Não se quer dizer com isso que as mulheres da Tribuna estivessem completamente alheias aos seus países de origem. A viagem de muitas delas foi financiada por fundações como Ford e Rockfeller, aliadas ao governo norte-americano, outras foram selecionadas e financiadas pelos seus próprios países, e havia aquelas, ainda, que atuavam como funcionárias públicas. Era esperado algum tipo de coordenação entre as deleg adas oficiais e as participantes da Tribuna; a relação entre governo e sociedade civil era complexa, portanto. De todo modo, os debates na Tribuna eram mais informais, as manifestações eram menos organizadas e era notória a espontaneidade das representantes nos seus discursos. Ver Olcott (2017).

8 Patricia Hutar, chefe da delegação dos Estados Unidos enviada à conferência intergovernamental, incluiu no relato da missão que o evento demonstr ou a existência de um movimento internacional de mulheres ("a worldwide women's movement"). Ver FRUS (2008d).
} 
direcionado ao financiamento de participantes de países em desenvolvimento. ${ }^{9}$ Essas mulheres levaram suas próprias narrativas e experiências, moldadas por histórias pessoais e coletivas de seus países de origem, por performances e expressões de identidade, e por formas distintas de entender como mudanças sociais deveriam ocorrer. Mulheres como Domitila Barrios de Chungara, esposa de um mineiro boliviano e ativista pelo direito das mulheres latino-americanas, Adriana Puiggrós, exilada argentina que denunciava as atrocidades cometidas na guerra suja do seu país, e Marisa de los Andes, ativista equatoriana contrária às políticas imperialistas norte -americanas, foram essenciais para levar à Tribuna outras vivências para além dos Estados Unidos ou da Europa (OLCOTT, 2017; LAVILLE, 2013; CHUNGARA, 1978).

As mulheresforam à Tribuna sem saber o que as esperava. Muitas compartilhavam a ideia de que seria um espaço livre, onde falariam sobre as opressões que lhes acometiam e conheceriam mulheres com experiências semelhantes de vida. Domitila de Chungara ansiava por conhecer na Tribuna companheiras com trajetórias parecidas com a sua: mulheres do campo e mulheres trabalhadoras, oprimidas e perseguidas (CHUNGARA, 1978, p. 197). A expectativa de que compartilhariam um sentimento de irmandadena Tribuna era comum (OLCOTT, 2017, p.139).

Não tardou para que essas expectativas fossem frustradas. O cuidado em assegurar a presença de mulheres de diferentes contextos no evento não se refletiu na própria organização da Tribuna. A elaboração do programa permaneceu nas mãos das norte-americanas e das europeias, que trataram de organizar os painéis conforme suas experiências e interesses. $^{10}$

As organizadoras buscaram garantir que o evento se mantivesse alheio a discussões políticas e focasse primordialmente na situação das mulheres - como o acesso ao mercado de trabalho e a posições de liderança, bem como o recebimento dos mesmos salários pagos aos homens em funções semelhantes. Para elas, debates políticos seriam forças estranhas ao feminismo e desviariam a atenção do principal assunto do evento - a desigualdade de gênero -, causando tumultos e dividindo as participantes (GHODSEE, 2018; LAVILLE, 2013). Esse entendimento era endossado, por exemplo, pelo Departamento de Estado dos Estados Unidos, que orientou a delegação norte-americana na conferência intergovernamental a manter o evento focado em "questões de mulheres" ("women 'sissues"). ${ }^{11}$

No entanto, o contexto da Guerra Fria e as diferentes origens das participantes trouxeram o inevitável tom polít ico aos debates. Na década de 1970, o Movimento dos Países Não Alinhados e a emergência de estados recém-independentes do colonialismo afro-asiático trouxeram pautas pouco exploradas na agenda das mulheres na ONU até aquele momento, entre as quais o impacto de políticas de desenvolvimento na vida das mulheres, a proteção das trabalhadoras, e a reivindicação por direitos reprodutivos. Essa agenda desafiou as duas superpotências da Guerra Fria, já que assumir a posição de liderança no direito das mulheres poderia aproximá-las dos estados não alinhados e dos novos países independentes, e, com isso, ampliar sua base de aliados e assegurar a defesa de seus interesses geopolíticos. Nesse contexto, a proteção dos direitos das mulheres converteu-se em ponto de intensa disputa da Guerra Fria, e o posicionamento das duas superpotências era diametralmente oposto: para a União Soviética, a situação da mulher não poderia ser dissociada de questões de classe e raça ou de debates sobre imperialismo; por outrolado, os Estad os Unidos argumentavam que essas questões de cunho político desviariam a atenção da luta contra a desigualdade de gênero (BORIS, 2018; GHODSEE, 2018; LAVILLE, 2013; LAVILLE, 2012). A Guerra Fria acabou, então, por ditar os debates na Tribuna, e discussões sobre direito das mulheres em meio a críticas ao governo de Pinochet no Chile, ao avanço das multinacionais norte-americanas na América Latina ou ao regime de apartheid na África do Sul se multiplicaram (GHODSEE, 2018, 2010;

\footnotetext{
9 A Primeira Conferência Mundial da Mulher recebeu um orçamento enxuto da ONU, se comparado com outros eventos - como a Conferência Mundial sobre População e Desenvolvimento, realizada em 1974. A Tribuna, por consequência, teve que operar sob um orçamento ainda mais diminuído. Ver Olcott (2017)

10 Antes mesmo do início da conferência intergovernamental e da Tribuna, o Departamento de Estado norte-americano já antecipava que assuntos como a Carta dos Direitos e Deveres Econômicos dos Estados e a Declaração e Programa de Ação sobre o Estabelecimento de Nova Ordem Econômica Internacional inevitavelmente emergiriam nos debates. Ver FRUS (2008b).

${ }^{11}$ Ver FRUS (2008b): “(...) os postos diplomáticos devem, conforme a oportunidade se apresente, e no curso de outras negociações, enfatizar o des ejo de que a WCIWY siga focada em questões de mulheres, de modo a evitar debates que se adequem melhor a outros foros da ONU” (tradução livre das autoras). No mesmo sentido, ver também FRUS (2008c).
} 
GARNER, 2017; OLCOTT, 2017; LAVILLE, 2013). ${ }^{12}$ Há relatos, inclusive, de que algumas mulheres não se aproximavam de outras que pertencessem a espectros ideológicos distintos dos seus (GHODSEE, 2010, p. 5).

As diferentes origens das participantes também contribuíram para que debates políticos fossem travados nesse espaço. De liberais norte-americanas a marxistas latino-americanas, diferentes existências e pensamentos ganharam visibilidade na Tribuna. A cientista política Jane Jaquette relata que as feministas norte -americanas ficaram surpresas ao descobrir que nem todas as participantes entendiam o patriarcado como a maior causa da opressão feminina, e que as mulheres de países em desenvolvimento eram mais simpáticas às ideias de Marx do que de Friedan (BALDEZ, 2014, p. 81). ${ }^{13}$

Logo, as participantes perceberam que muito as separava e se deram conta de que pouco se reconheciam nas outras mulheres. Em um momento bastante recordado na Tribuna, a boliviana Domitila de Chungara respondeu a uma participante mexicana que lhe questionava se não era possível encontrar pontos em comum e deixar para trás questões políticas que sobrestavam as discussões:

Nos conhecemos há uma semana. Todas as manhãs você chega vestida com roupas diferentes,e eu não. Todos os dias você chega arrumada e penteada como alguém que teve tempo de ir a um elegante salão de beleza e que pode gastar dinheiro com esse serviço, e eu não. (...) Ao contrário, nós, esposas de mineiros, vivemos em pequenas casas alugadas, e quando nossos maridos morrem, adoecem ou são demitidos, nós temos 90 dias para sair de casa e ir para a rua. Agora, señora, me diga: a sua situação é como a minha? A minha situação é de alguma forma parecida com a sua? Que equidade há entre nós duas? Se você e eu não somos iguais, se somos tão diferentes? Não podemos, nesse momento, ser iguais, nem mesmo como mulheres, você não acha? (CHUNGARA,1978, p. 202-203, tradução nossa)

Se para as liberais norte-americanas e europeias questões políticas seriam externas ao feminismo, e não passariam de mera tentativa de distração do que de fato as unia - a luta pela igualdade entre homens e mulheres -, para uma mulher como Domitila, essas mesmas questões eram parteintrínseca do feminismo. Para Domitila, não havia motivos para discutir equidade de gênero se os homens de seu país eram submetidos a uma existência tão precária quanto a das mulheres; de quelhe serviria a equidade se fosse para sua vida ser como a de seu marido, trabalhandolongas jornadas nas minas, sem condições mínimas de saúde e segurança, recebendo um salário que mal colocava comida na mesa para os filhos? Para ela, a situação das mulheres não poderia prescindir de debates sobre o fim do capitalismo e do imperialismo que legitimava multinacionais a explorar o povo boliviano e as riquezas naturais de seu país (GHODSEE, 2018; OLCOTT, 2017; CHUNGARA, 1978). Não havia espaço para negociação: ao entrecruzar relações de poder e desigualdade de gênero, Domitila utilizou a Tribuna para explorar a “transversalidade da conflituosidade social” (GAGO, 2020, p. 57).

Diante dessas diferenças, grupos se formaram na Tribuna. De um lado, mulheres de orientaçãoliberal reuniram se no Feminist Caucus em torno de uma agenda contrária à inclusão de pautas políticas e com foco na igualdade de oportunidades educacionais e de trabalho: "nossa opressão não nos dá o luxo de colocar um pouco de esforço aqui e ali, de nos dedicar a todas as causas importantes e ainda lutar contra o sexismo” (OLCOTT, 2017 p. 118, tradução nossa). No espectro oposto, um grupo de orientação Marxista denominado Women against Imperialism se recusava a discutir a situação das mulheres sem tratar de justiça econômica e social: "para você, a questão mais importante é emancipar-se e manter seu padrão de vida; para os subdesenvolvidos, é encontrar meios de nos alimentar” (OLCOTT, 2017 p.125, tradução nossa).

A Tribuna escancarou a existência de diferentes mulheres e feminismos. No entanto, a desunião não é uma característica negativa do evento (OLCOTT, 2017, p. 5). As diferenças podem ser ressignificada s como conquista: a Tribuna foi o local no qual essas mulheres conheceram umas às outras e fizeram-se visíveis. Deixaram seus países e reuniram-se em assembleia para debater as múltiplas violências que lhes afligiam; deram -se tempo político para compreender a iniquidade que marcava suas vidas, apropriando-se de sua luta como agentes políticos. Em meio à diversidade, tiveram

\footnotetext{
${ }^{12}$ Maxine Hitchcock, consultora norte-americana para o Ano Internacional da Mulher, relata como temas como o imperialismo norte-americano e a opressão norte-americana em Porto Rico e no Panamá de fato emergiram nas discussões da Tribuna. Ver FRUS (2008e).

${ }^{13}$ Em referência à Betty Friedan, conhecida ativista norte-americana de orientação liberal e autora do livro "The Feminine Mystique".
} 
contato com outras formas de viver e pensar, e, em conjunto, fizeram emergir verdadeira inteligência coletiva da Tribuna. Esse é o ponto que exploraremos a seguir.

\section{Mulheres em assembleia: a inteligência coletiva da Tribuna}

Para Verónica Gago (2020), os corpos transformam desejo em ação, e, assim, é fundamental para a potência feminista o lugar onde as mulheres se reúnem para reivindicar outro poder. No contexto das greves feministas, a autora explora a assembleia como espaço "onde a heterogeneidade política elabora suas diferenças, onde a escuta causa proximidade” (GAGO, 2020, p. 17). Para ela, a assembleia da greve é o espaço no qual as mulheres se encontram no fazer político, onde produzem conexões entre suas lutas, ainda que estas conexões não sejam espontâneas ou naturais.

Por ser esse espaço onde vidas heterogêneas se encontram e atuam politicamente, Verónica Gago argumenta que a assembleia é um "dispositivo situado de inteligência coletiva" (GAGO, 2020, p.187). Ali, antes da greve, as mulheres pensam juntas e avaliam sua situação, mas não sem mal-entendidos ou discordâncias. Pelo contrário, a inteligência coletiva emerge no debate entre perspectivas diferentes e se desenvolve a partir de uma perspectiva feminista sobre as múltiplas opressões sofridas pelas mulheres. Como cada mulher leva à assembleia sua própria experiência, expectativa, trajetória e memória, as palavras não se descolam de seus corpos; estão incrustadas neles, e deles emergem e são reconhecidas pelas outras. Daí ser a assembleia onde diferentes feminismos convivem e se compõem uns aos outros, tornando-se verdadeiramenteinclusivo: “(...) a produção da assembleia como encontro de conflituosidades diversas difere da assembleia como contraposição de opiniões e posições preexistentes.” (GAGO, 2020, p.197)

A Tribuna foi esse espaço de assembleia. Alifoi o lugar de encontro e debate em que as mulheres conheceramse umas às outras, depararam-se com diferentes formas de vida, e do qual emergiu verdadeira inteligência coletiva sobre a discriminação a qual todas eram submetidas. Assim comoVerónica Gago utiliza da greve feminista como chave de leitura insubmissa, fazemos o mesmo com a Tribuna, entendendo-a como elemento de desacato, e local onde as relações de poder são evidenciadas e compreendidas, onde os corpos nos quais tais relações se aplicam são revelados e ousam desobedecer aos papeis que lhes foram impostos (GAGO, 2020, p. 55).

A Tribuna foi, assim, espaço para encontro de conflituosidades. Isso porque o evento aconteceu no mundo real envolvendo pessoas de diferentes origens e orientações, trazendo suas próprias experiências pessoais (WHITAKER, 1975). Muitas alertaram sobre outras opressões para além da violência de gênero. Tomaram conhecimento da existência de outras formas de viver e de pensar a luta feminista. Não chegaram a um consenso sobre quais debates deveriam ser realizados no âmbito do movimento feminista. No entanto, entre tantas diferenças, se (re)conheceram na Tribuna. Ruth Bacon conselheira da delegação norte-americana presente na Tribuna - relata que a despeito de tanta diversidade, havia uma perceptívelinquietação comum e que este sentimento coletivo seria um dos principais legados do evento. ${ }^{14}$

Na Tribuna, as participantes levaram seus corpos como manifestação política, nacional, ideológica e étnica (OLCOTT, 2010). Nesse encontro, uma similitude foi encontrada: a discriminação cotidiana. Jill Ruckelshaus, integrante da delegação norte-americana na conferência em contato direto com as participantes da Tribuna, enalteceu o evento por chamar a atenção do mundo para “(...) a falta de oportunidades que as mulheres enfrentavam em todos os lugares” (SPRUILL, 2017, tradução nossa).

Ao reconhecer a precariedade comum, tornam-se parte de um movimento. Era disseminado entre elas o sentimento de que lhes era reservado o cuidado da casa e dos filhos. A elas cabia o trabalho reprodutivo o doméstico era o seu ambiente natural. Aquelas que por opção ou por necessidade trabalhassem fora de casa - que também exercessem trabalhos produtivos -, ainda assim deveriam manter o lar: limpando, cozinhando, e cuidando das crianças e idosos. Em

\footnotetext{
${ }^{14}$ Ver FRUS (2008f): "O contato com a diversidade e a compreensão de que sob as diferenças havia uma preocupação universal comum entre as mulheres presentes foram os primeiros e mais duradouros impactos da Tribuna nas mulheres norte-americanas com quem eu conversei” (tradução nossa).
} 
qualquer cenário, o trabalho doméstico era diminuído, invisibilizado e não remunerado. Discussões sobre o peso da dupla jornada e a escravidão doméstica se multiplicaram pela Tribuna, e a campanha para o pagamento de salários pelos serviços domésticos emergiu em diversos círculos. Era em momentos como esses que elas reconheciam uma similaridade crítica: 0 volume excessivo de trabalho que recaía sobre os ombros das mulheres que era excluído dos dados econômicos dos países (OLCOTT, 2017, p. 143), comose fosse desprovido de valor.

Debates sobre trabalho reprodutivo não raro envolviam discussões sobre padrões culturais. O fardo do trabalho doméstico era justificado pela divisão sexual do trabalho: às mulheres o privado, aos homens o público. Os homens exerciam papel ativo na manutenção de padrões culturais que serviam de justificativa para a subordinação feminina. É emblemático os comentários feitos por um homem membro da delegação soviética sobre a dupla jornada, e a manifestação de uma delegada romena. Para ele, era notável a dificuldade das mulheres em equilibrar o trabalho para além do lar e o cuidado com a casa e os filhos, mas, na sua percepção, “(...) esse papel duploé de muita honra para uma mulher”. Para ela, o sentimento era outro: "Estamos exaustas de lutar pela divisão do trabalho” (WHITAKER, 1975, p. 179, tradução nossa).

É claro que os sentimentos comuns de invisibilização e de desvalorização provenientes do trabalho doméstico não apagam as diferentes histórias das participantes. As mulheres carregavam consigo experiências distintas, e o peso do trabalho doméstico também era sentido de forma diferente por elas. Para algumas delas, o trabalho doméstico envolvia longas caminhadas diárias para a busca de lenha e água em poços artesianos, o cuidado de plantações de subsistência,e a criação de animais para abate - atividades estranhas às mulheres de centros urbanos. Além disso, as opressões se somam e interagem, tornando algumas existências mais difíceis que outras: ademais da dupla jornada, mulheres negras enfrentam o racismo, e mulheres de classes sociais baixas preocupam-se em como pagar o aluguel e alimentar os filhos.

É evidente que as mulheres tampouco concordavam em como lidar com o fardo do trabalho doméstico. Para Domitila de Chungara, discussões sobre dupla jornada e recebimento de salário pelotrabalhoreprodutivo seriam inúteis sem repensar o sistema capitalista. Mulheres dobloco soviético insistiam no envolvimento do Estado para aliviar o fardo do trabalho reprodutivo - criação de creches públicas, refeitórios comunitários, etc. -, enquanto nos Estados Unidos o presidente Nixon havia há pouco vetado um sistema público de creches (GHODSEE, 2018; OLCOTT, 2017; CHUNGARA, 1978)..$^{15}$

Apesar das realidades diversas em que viviam e das diferentes formas de pensar, o desejo de serem vistas para além do doméstico, de ocupar outros espaços e reivindicar outro futuro, as impulsionou a ir à Tribuna. Impossível deixar de notar como a inteligência coletiva que emergiu da discriminação comum dialoga com os debates realizados por Gago (2020) ao teorizar a potência feminista: o aspecto material é debatido em termos próximos àqueles que emergiram na Tribuna em 1975. A invisibilização e a gratuidade do trabalho reprodutivo, bem como a limitação ao ambiente doméstico, foram fundamentais para o diagnóstico de uma precariedade comum na Tribuna, como também foram cruciais para conduzir as mulheres às greves feministas quarenta anos depois.

Não é de se espantar, assim, que os eventos no México tenham sido vistos como "o início de uma consciência global sobre o valor das mulheres” por quem pôde estar ali presente. ${ }^{16}$ Resta agora discutir como as mulheres, munidas dessa consciência global, retornam para suas casas e difundiram as ideias debatidas na Tribuna, a partir de suas particularidades.

\footnotetext{
${ }^{15}$ Trata-se do Comprehensive Child Development Act. Em 1971, o presidente Nixon vetou o projeto por entender que, dentre outros motivos, a legislação levaria ao enfraquecimento da família, diante da abordagem comunal para a criação das crianças que a lei traria. Ver Rosenthal (1971).

${ }^{16}$ Ruth Bacon relata ao Secretário de Estado norte-americano Henry Kissinger que os eventos no México "(...) mark a true beginning of "world-wide awareness of women's worth.” (...)”. Ver FRUS (2008f).
} 


\section{A Tribuna como arena de difusão internacional de ideias}

Além de locus para o desenvolvimento da inteligência coletiva, a Tribuna também foi importante arena de difusão internacional de ideias dos movimentos feministas, e as mulheres ali presentes atuaram como "agentes” de transferência e difusão. ${ }^{17}$ A Tribuna gerou um legado que ultrapassou fronteiras e gerações, repercutindo nos feminismos contemporâneos e na potência feminista.

Estudos sobre difusão internacional ajudam a compreender como eventos nos moldes da Tribuna têm uma importância estratégica - muitas vezes invisibilizada - em circular ideias e, consequentemente, impactar a política doméstica dos países de origem dos participantes. A literatura sobre difusão reforça que essas interações internacionais de atores governamentais e não governamentais, às vezes de forma orgânica, às vezes de forma intencional, favorecem a circulação de ideias e a geração de inovações ao associar contribuições de origens diferentes (OLIVEIRA, 2013).

Segundo Dolowitz e Marsh (2000, p. 12) “quase tudo” pode ser transferido de um sistema político para outro: objetivos, conteúdos e instrumentos de política, programas, instituições, ideias, ideologias e, inclusive, lições negativas. Essa transferência pode ocorrer em circulações “contínuas, transnacionais, multi-escalar e multi-stakeholder” (STONE; OLIVEIRA; PAL, 2020, p. 4, tradução nossa).

Para entender a Tribuna como arena de difusão internacional de ideias feministas, e como seu legado repercute na potência feminista, fazemos referência à Oliveira e Pal (2018) e discutiremos o evento a partir de três aspectos: (i) o espaço transnacional de difusão; (ii) as agentes de transferência; e (iii) a tradução das ideias difundidas.

\section{A Tribuna como espaço transnacional de difusão}

Eventos transnacionais sem “territorialidade específica” são importantes espaços de difusão, por se tratarem de lugares de produção, circulação e legitimação de ideias (OLIVEIRA; PAL, 2018, p. 207; OLIVEIRA; FARIA, 2017, p. 15).

Ainda que o movimento internacional de mulheres conte com mais de 150 anos, True e Mintrom (2001, p. 38) ressaltam que a década da ONU para as mulheres, de 1975 a 1985, marcou uma nova era no ativismo transnacional feminino. A estrutura de debates e encontros promovida pela ONU na Tribuna possibilitou um rico local de construçãoe difusão de ideias. Foi ali que mulheres dos mais diversos lugares do mundo encontraram -se e debateram a sua própria situação. É na Cidade do México que a desigualdade feminina se torna, pela primeira vez, o objeto central de debates transfronteiriços.

O potencial da Tribuna como um local de aprendizagem, ensino e compartilhamento sobre a situação da mulher era perceptível para aqueles presentes no evento:

Após a euforia da tribuna, muitos ativistas compartilharam a visão de um participante de que ela tinha "um potencial fantástico como um dispositivo frutífero de aprendizagem-ensino-compartilhamento e até mesmo talvez como um embrionário 'parlamento do mundo' tanto para pressionar o progresso de governos impassíveis quanto para mobilizar um consenso internacional vital e a vontade política dos grupos afetados de agir (OLCOTT, 2017, p. 231, tradução nossa).

Ruth Bacon, ao reportar seus dias na Tribuna, exalta o evento como uma valiosa oportunidade de aprendizado. Para ela, muitas das mulheres jamais haviam tido a oportunidade de discutir pessoalmente suas preocupações e anseios para além das fronteiras nacionais. Diferentemente da conferência intergovernamental, as mulheres na Tribuna “(...) integravam movimentos de base, e o impacto de suas experiências seriam amplamente difundidos nacionalmente” (traduçãonossa).

\footnotetext{
${ }^{17}$ Cabe aqui fazer uma distinção entre difusão e transferência internacional. Apesar dos diversos entendimentos e falta de consenso sobre esta distinção, usaremos a definição trazida por Gonnet, Oliveira e Vergara, que tratam a difusão como um fenômeno mais "macro", relacionado à circulação ampla de ideias. Já a transferência seria mais direcionada e proporcionaria aos países os mecanismos para operacionalizar tais ideias. Nesse sentido, ver Gonnet, Oliveira e Vergara, 2020, p. 22.
} 


\section{As mulheres na Tribuna comoagentes de transferência}

O sucesso da Tribuna dependia do protagonismo das participantes na construção, circulação e legitimação de ideias, e isso somente aconteceria se as organizadoras abrissem mão do controle sobre os debates e as deixassem livres para tratar de sua própria condição - o que, de fato, aconteceu (OLCOTT, 2017). Esse ponto foi essencial para a difusão das ideias ali debatidas.

Stone, Oliveira e Pal (2020) chamam a atenção para o papel estratégico de atores não governamentais nos processos de difusão: os “soft actors”. Para eles, difusão é um processo que inclui manifestações cotidianas de resistência,e a sociedade civil, mantendo uma relação complexa, porém imbricada com a burocracia oficial, acaba por ter um papel central em legitimar práticas de origens internacionais.

A Tribuna não foi o único espaço de difusão de ideias dos movimentos feministas. No entanto, é na Tribuna que se vê, pela primeira vez em escala global, o embrião da estruturação de uma rede transnacional de mulheres: é olocal onde se encontram, se reconheceme se estranham.

Além disso, já se entendia, naquele momento, o papel das participantes na transferência e tradução, para realidades locais, das ideias apreendidas. Helvi Sipilä, secretária geral da conferência, em discurso na Tribuna, encorajou as mulheres a pressionar os governos nacionais a adotarem o Plano de Ação, incentivando -as, ainda, a seguir com os laços criados no México e desenvolver uma rede de mulheres para acompanhar a execução das diretrizes acordadas entre os representantes de Estado. ${ }^{18}$

Com efeito, após os eventos do Ano Internacional das Mulheres, processos de difusão de "gender mainstreaming" rapidamente se proliferaram. ${ }^{19}$ True e Mintrom (2001) propõem-se a entender as possíveis variáveis que teriam contribuído com a rapidez dessa difusão, e concluem que, para o período de 1975 e 1998, e considerando uma amostra de 157 países, 110 adotaram algum tipo de instituição de “gender mainstreaming”, e que, a principal força motriz dessa difusão foram as redes transnacionais de atores não estatais - mais do que dinâmicas e aspectos locais, ou pressões internacionais e intergovernamentais. Os autores enfatizam, ainda, que desde 1975 essas redes de organizações de mulheres proporcionaram momentum político e pressões sociais capazes de provocar mudanças institucionais significativas sobre a questão de gênero no nível doméstico. Um exemplo disso, analisado por Towns (2012) é o estabelecimento de quotas para mulheres, demandadasinicialmente por movimentos sociais latino-americanos, a partir da década de 80, que emergiram como resultado da difusão do tema a partir das discussões sobre participação política feminina durante a Década da Mulher da ONU.

\section{A tradução de ideiase suas consequências}

O termo "tradução" é disputado entre os autores. Zwingel (2012,p.124) analisa a tradução de normas de direitos das mulheres a partir da Convenção sobre a Eliminação de Todas as Formas de Discriminação contra as Mulheres CEDAW. Para ela, a tradução "permite diferentes caminhos de encontros transculturais e transmissões de significado, mas o termo também inclui desigualdade - o enriquecimento mútuo é possível tanto quanto a subordinação”.

Para Oliveira e Pal (2018, p. 209), o processo de tradução produz mudanças, no tempo e no espaço, tanto nos componentes materiais como na dimensão abstrata do que é transferido, pois, sem alguma tradução, o objeto da difusão não se encaixaria em contextos diferentes ou seria aceito por grupos heterogêneos. Stone, Oliveira e Pal (2020, p. 14) sugerem, ainda, que a tradução se inicia quando a política ou ideia ainda está circulando, antes mesmo de "aterrissar" em um contexto específico, pois diferentes atores aportam diferentes interpretações ao processo, mesmo antes de a

\footnotetext{
${ }^{18}$ Ver FRUS (2008e).

${ }^{19}$ Segundo Guenther (2008, p. 590), "gender mainstreaming" significa repensar novas abordagens para a formulação de políticas a partir da perspectiva de gênero. Nesse sentido, busca-se compreender as maneiras pelas quais as políticas nos diversos níveis de governança podem afetar de formas diferentes mulheres e homens, e, ao deparar-se com essas diferenças, corrigi-las.
} 
transferência ser completada. A partir daí, a ideia consistirá “(...) em misturas, amálgamas e ligas híbridas ou, possivelmente, na coexistência não reconhecida de princípios contraditórios”. Essa perspectiva é uma forma de considerar a volatilidade dos processos, e sua multiplicidade de atores e contextos, de forma a descontruir a crítica a respeito de uma possível homogeneização gerada pela difusão internacional (ENGBERG-PEDERSEN et al, 2019).

Justamente por essa característica tão dinâmica e complexa, Stone, Oliveira e Pal (2020) reconhecem a dificuldade em estabelecer causalidade direta nos processos de difusão, ou previsibilidade de padrões, seja em razão dos inúmeros intermediários e caminhos de adaptação, seja por conta da "personalização" que ocorre durante a circulação e tradução do objeto da difusão. Dessa forma, retoma -se a Dolowitz e Marsh (2000) que defendem a relevância de usar a difusão como uma variável explicativa (ainda que não a única), mas que, para isso, faz-se necessário compreender e explicar o processo de difusão: o que é transferido, por quem e por quê, o que pode também ser chamado de "rastreamento" (OLIVEIRA, 2016).

Há diversos exemplos desse rastreamento e tradução de ideias a partir da Tribuna. A proliferação de organizações não governamentais, como a criação do coletivo mexicano de mulheres feministas, La Revuelta, e da revista de mesmo nome que abordava temáticas feministas, demonstra que a articulação em redes nãoé apenas um mecanismo de difusão de ideias, mas também uma forma de fortalecer as próprias organizações, que passam a fornecer contatos internacionais, oportunidades de capacitação, estrutura e financiamentos. Ainda, a Tribuna proporcionou a consolidação de uma rede de mulheres na América Latina, culminando, em 1981, no Encuentro Feminista Latinoamericanoy del Caribe, em Bogotá. As feministas Latino-Americanas incorporaram à sua luta os esforços anticapitalistas e o comprometimento pelas causas sociais e pelas demandas dos setores oprimidos, herança das ideias que circularam pela Tribuna (OLCOTT, 2017).

A potência feminista de Verónica Gago traz também um exemplo de tradução de ideias da Tribuna. Veja-se, por exemplo, o debate que a autora apresenta sobre a economia feminista, apresentado anteriormente nesse artigo. Para ela, incluir a divisão sexual do trabalho na noção de economia nos permite não só conceitualizar e medir a diferente exploração sentida por mulheres, lésbicas, trans e travesti, mas, também, desacatar, subverter e transformar o capitalismo, marcado por heranças coloniais e patriarcais. Gago (2020, p. 143) reclama a visibilização do trabalho feminino não remunerado e das tarefas feminizadas para repensar o capitalismo, e, para tanto, urge que as mulheres não sejam meramente incorporadas às análises econômicas:

Outra vez: não se trata de uma análise setorizada e que interessa apenas a uma "minoria” (...), mas de uma perspectiva singular na qual se visualiza o conjunto a partir de uma conflituosidade concreta. Isso supõe metodologicamente que as mulheres e os corpos feminizados não são um capítulo a ser agregado à análise econômica, mas que oferecem uma perspectiva que reformula a análise econômica em si; uma leitura política transversal que propõe outra entrada à crítica da economia política, e não uma agenda limitada.

Gago vai além ao desenvolver seu argumento, mas é impossível não traçar um paralelo com as participantes da Tribuna que, ao sugerir alterações no Plano de Ação debatido entre os representantes governamentais na conferência, criticam como as mulheres foram demasiadamente tratadas como unidades econômicas: "As revisões propostas são de natureza prática e construtiva, e refletem, em parte, o entendimento de que a minuta do Plano apresentado pelo Secretariado da ONU tratava as mulheres excessivamente como uma unidade econômica sem que levasse em conta, adequadamente, outras necessidades e aspirações femininas”. ${ }^{20}$

Para as participantes na Tribuna, como para Verónica Gago, olhar para as mulheres como uma unidade econômica não resolveria sua situação de precariedade. É necessário entendê-las como sujeitos com aspirações e anseios próprios, muito além do doméstico e do reprodutivo - gratuito, menosprezado e apresentado comoúnica opção.

${ }^{20}$ Ver FRUS (2008f), tradução nossa. 
Nesse sentido, é impossível não se recordar das palavras de Domitila Chungara quandoVe rónica Gago diz: "Não queremos diminuir a brecha para que sejamos tão exploradas quanto os homens” (GAGO, 2020, p. 143). Tanto para a ativista boliviana, como para a teórica argentina, não basta inserir as mulheres no mesmo sistema econômico que oprime os homens.

Verónica Gago explora a economia feminista para pensar em alternativas à mera inclusão das mulheres no mesmo sistema econômico que também subjuga os homens, e o faz no contexto argentino. Explora a coletivização do cuidado e do trabalho reprodutivo quando a sociedade se afundou, em 2001, em uma das mais graves crises econômicas da história argentina.

Percebe-se, assim, que as ideias de Verónica Gago, debatidas no âmbito da potência feminista, encontram paralelo com as ideias das mulheres presentes na Tribuna. A autora traduz essas ideias para a realidade argentina, mas o fio condutor entre elas não se perde.A Tribuna foi a arena de onde as mulheres, como agentes, difundiram internacionalmente múltiplas vozes e ideias, traduzidas, ainda hoje, nos debates e movimentos feministas.

\section{Considerações finais}

Verónica Gago (2020) apresenta a potência feminista como teoria alternativa de poder. Para ela, a potência feminista significa reclamar às mulheres a indeterminação do que podem ser. Imbuídas do desejo de transformar tudo que lhes foi imposto, vindicam para si um lugar para além do domésticoe da dependência social e financeira.

A potência feminista é teorizada a partir de um evento contemporâneo: as greves feministas. No entanto, a autora reconhece que a potência é um pensamento que deve ser situado como parte de uma sequência de lutas. Vimos, assim,uma lacuna a ser explorada: olhar para o passado para melhor compreender o presente. Nesse sentido, nos propusemos a dar um passo atrás e resgatar o embrião da potência feminista em um evento pioneiro de grande relevância na luta pela igualdade: a Tribuna. Ali, pela primeira vez, mulheres das mais diferentes origens se reuniram em um evento internacional para discutir a sua situação.

Ao revisitar os encontros na Tribuna, é impossível não enxergar naquelas mulheres o mesmo desejo de mudança que Verónica Gago (2020) teorizou décadas mais tarde. As diferenças entre as mulheres foram escancaradas. Ainda assim, a inteligência comum da precariedade de suas vidas e o desejo de transformar as estruturas de poder que as submetia a papéis escolhidos pelo outro é manifesto. A potência e o desejo teorizados pela autora moveram as mulheres na Tribuna, e os resultados encontrados corroboram a ideia de que a potência feminista é também situada em lutas passadas: o desejo de mudar tudo é claramente identificado em um evento realizado nos anos 1970. As origens da teoria são mais antigas, portanto, e carregam consigo o peso de uma longa luta.

A luta feminista é um processo. As mulheres que foram à Tribuna deram passos importantes no debate de questões que ainda hoje são foco de estudo e mobilizam ação. Em sua heterogeneidade, interagiram naquele espaço transnacional, circulando e modificando ideias e pontos de vista que foram traduzidos a suas realidades locais. Contribuíram com a internacionalização da política feminista, que se firmou no cenário internacional em conferências subsequentes dedicadas à situação das mulheres. ${ }^{21} \mathrm{~A}$ potência e o desejo de reivindicar um novo futuro seguem orientando as mulheres nas greves feministas, nas assembleias, nos encontros para demandar vidas menos precárias. É a partir do legado das mulheres da Tribuna que a luta continua.

\footnotetext{
${ }^{21}$ A ONU realizou outras conferências dedicadas às mulheres em Copenhague (1980), Nairóbi (1985), e Pequim (1995). A Tribuna, em especial, contribuiu para a solidificação de uma rede de mulheres, bem como serviu de aprendizado e inspiração para os eventos da sociedade civil realizados em paralelo às conferências da mulher. Ver Friedman (2003).
} 


\section{Referências}

BALDEZ, L. Defying Convention: US Resistance to the UN Treaty on Women's Rights. Nova Iorque: Cambridge University Press, 2014.

BORIS, E. Equality 's Cold War: The ILO and the UN Commission on the Status of Women, 1946 -1970s. In:BORIS, E; et. al. Women 's ILO. Leiden: Brill, 2018, cap. 4, p. 97-120.

BUTLER, J. Corpos em aliança e a política das ruas: notas para uma teoria performativa da assembleia. Rio de Janeiro: Civilização Brasileira, 2018.

CHUNGARA, D. Let me Speak! Testimony of Domitila, a woman of the Bolivian mines. Nova Iorque: Monthly Review Press, 1978.

DOLOWITZ, David P.; MARSH, David. Learning from abroad: the role of policy transfer in contemporary policy-making. Governance: An International Journal of Policy and Administration, Oxford: v. 13, n. 1, p. 5-24, January 2000.

ENGBERG-PEDERSEN et al. Rethinking Gender Equality in Global Governance: The Delusion of Norm Diffusion. Londres: Palgrave MacMillan, 2019.

FEDERICI, Silvia. O ponto zero da revolução: trabalho doméstico, reprodução e luta feminista. São Paulo: Elefante, 2019.

FRIEDMAN, E. Gendering the Agenda: The Impact of the Transnational Women's Rights Movement at the UN Conferences of the 1990s. Women's Studies International Forum, Amsterdam: v. 26, p. 313-331, 2003.

FOREIGN RELATIONS OF THE UNITED STATES (FRUS), 1969-1976, Volume E-14, Part 1, Documents on the United Nations, 1973-1976, eds. William B. McAllister and Edward C. Keefer. Washington: Government Printing Office, documents 165 -190,2008. Disponível em: https://history.state.gov/historicaldocuments. Acesso em 7/7/2021.

FOREIGN RELATIONS OF THE UNITED STATES (FRUS), 1969-1976, Volume E-14, Part 1, Documents on the United Nations, 1973-1976, eds. William B. McAllister and Edward C. Keefer.Washington: Government Printing Office, document n. 170, "Telegram 383 From the Mission to the United Nations to the Department of State”, February 4,1974,1954z”, 2008 a.

FOREIGN RELATIONS OF THE UNITED STATES (FRUS), 1969-1976, Volume E-14, Part 1, Documents on the United Nations, 1973-1976, eds. William B. McAllister and Edward C. Keefer. Washington: Government Printing Office, document n. 178, “Telegram 119806 Fr om the Department of State to All Diplomatic Posts”, May 22, 1975, 1823z, 2008b.

FOREIGN RELATIONS OF THE UNITED STATES (FRUS), 1969-1976,Volume E-14, Part 1, Documents on the United Nations, 1973-1976, eds. William B. McAllister and Edward C. Keefer. Washington: Government Printing Office, document n. 179, “Telegram 126689 Fr om the Department of State to the Mission to the United Nations”, May 30,1975,2325z, $2008 \mathrm{c}$.

FOREIGN RELATIONS OF THE UNITED STATES (FRUS), 1969-1976, Volume E-14, Part 1, Documents on the United Nations, 1973-1976, eds. William B. McAllister and Edward C. Keefer. Washington: Government Printing Office, document n. 182, "Conclusions to the Report of the United States Delegation to the World Conference of the International Women 's Year”, undated,2008d.

FOREIGN RELATIONS OF THE UNITED STATES (FRUS), 1969-1976, Volume E-14, Part 1, Documents on the United Nations, 1973-1976, eds. William B. McAllister and Edward C. Keefer. Washington: Government Printing Office, document n. 184, "Report on "The Tri bune Speakout” United Nations World Conference of the International Women's Year”, July 18, 1975, 2008e.

FOREIGN RELATIONS OF THE UNITED STATES (FRUS), 1969-1976, Volume E-14, Part 1, Documents on the United Nations, 1973-1976, eds. William B. McAllister and Edward C. Keefer. Washington: Government Printing Office, document n. 185, "Letter from the Director of the United States Center for the International Women's Year (Bacon) to Secretary of State Kissinger”, Washington, July 24, 1975, $2008 f$.

GAGO, V. A potência feminista, ou o desejo de transformar tudo. São Paulo: Editora Elefante, 2020.

GARNER, K. Global Feminism and Cold War Paradigms: Women's International NGOs and the United Nations, 1970 -1985. In: MUEHLENBECK, P. Gender, Sexuality, and the Cold War: A Global Perspective. Nashville: Vanderbilt University Press, 2017, cap. 11, p. 224-248.

GHODSEE, K. Second world, second sex: socialist women 's activism and global solidarity during the Cold War. Durham: Duke University Press, 2018.

GHODSEE, K. Revisiting the United Nations decade for women: Brief reflections on fe minism, capitalism and Cold War politics in the early years of the international women's movement. Women's Studies International Forum, Amsterdam:v. 33, p. 3-12, 2010.

GONNET, O.; OLIVEIRA, M. C.; VERGARA,J. M. International development cooperation as on ef the triggers for the process of public policy transfer. Estudos Internacionais. Minas Gerais, v. 8, n. 2, p.8-26, 2020.

GUENTHER, K. M. Understanding policy diffusion across Feminist Social Movements: The case of gender mainstreaming in Eastern Germany. Politics \& Gender, Cambridge: v. 4, p. 587-613, 2008. 
LAVILLE, H. Gender and Women's Rights in the Cold War. In: IMMERMAN, R.; GOEDDE, P. The Oxford Handbook of the Cold War. Oxford: Oxford Press, 2013, p. 524-539.

LAVILLE, H. 'Wooly, Half-Baked and Impractical?' British Responses to the Commission on the Status of Women and the Convention on the Political Rights of Women 1946-67. Twentieth Century British History, Oxford: v. 23, n. 5, p. 473-495, 2012.

LAVILLE, H.A New Era in International Women's Rights?: American Women's Associations and the Establishment of the UN Commission on the Status of Women. Journal of Women's History, Baltimore: v. 20, n. 4, p. 34-56,2008

MAIA, S. De Foucault a Butler: identidade(s), performatividade e normatividade de gênero. In: MARTINS, M.; MACEDO, I. Livro de atas do III Congresso Internacional sobre Culturas: Interfaces da Lusofonia. Braga: CECS, 2019, p. 417-428.

MCCARTHY, H. The Diplomatic History of Global Women's Rights: The British Foreign Office and International Women's Year, 1975. Journal of Contemporary History, Londres: v. 50, n. 4, p. 833-853, 2015

OLCOTT, J. International Women's Year: the greatest consciousness-raising event in history. Nova Iorque: Oxford University Press, 2017.

OLCOTT, J. Cold War Conflicts and Cheap Cabaret: Sexual Politics at the 1975 United Nations International Women's Year Confer ence. Gender \& History, New Jersey: v. 22, n. 3, p. 733-754, 2010.

OLIVEIRA, O. Embaixadores da Participação: a difusão internacional do orçamento participativo do Brasil. Tese de Doutorado, Departamento de Ciência Política da Faculdade de Filosofia, Letras e Ciências Humanas da Universidade de São Paulo, Brasil, 2013 , 292p.

OLIVEIRA, O.; FARIA, C. Policy Transfer, Diffusion and Circulation: Research Traditions and the state of the Discipline in Brazil. Novos Estudos. São Paulo, v. 36, , p. 13-32, março 2017.

OLIVEIRA, O.; PAL L. Novas fronteiras e direções na pesquisa sobre transferência, difusão e circulação de políticas públicas: agentes, espaços, resistência e traduções. Revista de Administração Pública (RAP). Rio de Janeiro 52 (2), p. 199-220, mar. - abr. 2018.

ORGANIZAÇÃO DAS NAÇÕES UNIDAS (ONU). Assembleia Geral. Resolução 3010 (XXVII), 18 de dezembro de 1972. Dispon ível em: https://digitallibrary.un.org/. Acesso em 7/7/2021.

ORGANIZAÇÃO DAS NAÇÕES UNIDAS (ONU). Assembleia Geral, Resolução 31/136, 16 de dezembro de 1976. Disponível em: https://digitallibrary.un.org/. Acesso em 7/7/2021.

ORGANIZAÇÃO DAS NAÇÕES UNIDAS (ONU). Report of The World Conference of the International Women 's Year, Mexico City: 19 June-2 July, 1975. Disponível em: https://digitallibrary.un.org/record/586225. Acesso em 21/7/2021.

RODRIGUES, C. Três tempos da performatividade em Butler. In: CATTONI, M.; VIANA, I. Políticas da Peformatividade Conferências. Belo Horizonte: Conhecimento Livraria e Editora, 2019, cap. 2, p. 29 -42.

ROSENTHAL, J. President Vetoes Child Care Plan as Irresponsible. The New York Times. Nova Iorque, 10 de Dezembro de 1971. Disponível em: https://www.nytimes.com/1971/12/10/archives/president-vetoes-child-care-plan-as-irresponsible-he-terms-bill.html. Acesso em 7/5/2021.

SPRUILL, M. Divided We Stand: The Battle Over Women's Rights and Family Values that Polarized American Politics. Nova Iorque: Bloomsbury, 2017.

STONE, D.; OLIVEIRA, O.; PAL L. Transnational policy transfer: the circulation of ideas, power and development models, Policy and Society, London: v. 39, n. 1, p.1-18, 2020.

TOWNS, Ann. E. Norms and Social Hierarchies: Understanding International Policy Diffusion "From Below". International Organization, Cambridge:v. 66,n. 2, p.179-209,2012.

TRACHTENBERG, M. The craft of international history: a guide to method. New Jersey: Princeton University Press, 2006.

TRUE, J.; MINTROM, M. Transnational Networks and Policy Diffusion: The case of Gender Mainstreaming. International Studies Quaterly, Oxford: v. 45, p.27-57, 2001.

VILAÇA, M.; FREITAS, B. A Potência dos Feminismos na Luta contra a Razão Neoliberal na América Latina: uma entrevista com Verónica Gago. Política \& Trabalho. João Pessoa, n. 52, p. 231-245, 2020.

WHITAKER,J. Women of the World: Report from Mexico City. Foreign Affairs. Nova Iorque, v. 54, n. 1, p. 173-181, 1975.

ZWINGEL, Susanne. How Do Norms Travel? Theorizing International Women's Rights in Transnational Perspective. International Studies Quarterly, Oxford: v. 56, p.115-129, 2012. 
Funções de colaboração exercidas

Natali Francine Cinelli Moreira:

Kelly KomatsuAgopyan:
Conceituação; Metodologia; Curadoria de dados; Administração do projeto; Investigação; Escrita (primeira redação); Escrita (revisão e edição);

Conceituação; Metodologia; Curadoria de dados; Administração do projeto; Investigação; Escrita (primeira redação); Escrita (revisão e edição);

Informações fornecidas pelos(as) autores(as) de acordo com a Taxonomia de Funcões de Colaborador (CRediT) 